\title{
Melilla en la visión de la novela histórica: 1921 (Aproximación en tres textos)
}

\author{
Por Vicente Moga Romero
}

\author{
"Pasa el tiempo la lluvia de los dfas \\ todo lo borra, ¿quién recuerda ahora \\ los Ambar, y Taxuda, y Casabona; \\ Tauriat-Hamet, y el Blocao de la Muerte...? \\ ¡Hojas arrebatadas por ardiente \\ ábrego; agua pasada que no muele...!"

\section{LA NOVELA HISTORICA COMO PRE-TEXTO}

Asistimos hoy al resurgir de la llamada novela histórica. Para algunos no es más que la moda del neorromanticismo que quiere envolvernos. Para otros, no sería más que el desarrollo de un género que apenas si tiene limitaciones. En efecto, desde la Ciropedia de Jenofonte, la novela histórica se ha ido afirmando hasta poderse decir que "toda novela es historia, toda noveda es novela histórica... Todo escritor escribe en la historia, aunque ciertamente no todos los escritores hagan historia ni tengan por qué hacerla: la relación del escritor con la historia es, ni más ni menos, su relación con la realidad. No se está en la realidad, es decir, no se está en el mundo, si no se está en la historia" (2).

Por supuesto la novela histórica puede constituir una deformación de la verdad histórica, pero la misma Historia ha de incluirla entre sus fuentes, aunque con la consideración de fuentes "indirectas" y sujetas a todo tipo de comprobaciones. Además, los historiadores han sentido la tentación de

(1) SANTA MARINA, Luys, Tras el dguila del César. Elegta del Tercio, 1921-1922. Ed. Planeta, Barcelona, 1980, pág. 199.

(2) HINTERHAUSER, Hans, Los Episodios Nacionales, de Benito Perez Galdós. Gredos, Madrid, 1963. G tado en SUEIRO, Daniel: La novela historica como forma de acción. Historia-16, núm. 73, Madrid, 1982, págs. 110 a 114. 
novelar la historia, porque asf encuentran "la oportunidad de sumergirse en la experiencia emotiva y sus sugerencias, en un contexto dado" (3). En este sentido, la novela histórica ha evolucionado desde el Romanticismo hasta hoy. Y lo ha hecho, en primer lugar, apoyando la vocación por los estudios históricos en la época del Romanticismo, reflejando los progresos de la ciencia histórica en el siglo XIX (Flaubert, Tolstoi, Pérez Galdós...), generando una biografía novelada que aporta tanta historia como recibe (4).

Marguerite Yourcenar en el "Cuaderno de notas" que sirve de apéndice a su novela sobre Adriano aclara el panorama, situándolo en sus coordenadas más actualizadas: "Los que consideran la novela histórica como una categoría difernte olvidan que el novelista no hace más que interpretar, mediante los procedimientos de su época, cierto número de hechos pasados, de recuerdos conscientes o no, personales o no, tramados de la misma manera que la Historia. Como Guerra y Paz, la obra de Proust es la reconstrucción de un pasado perdido. La novela histórica de 1830 cae, es cierto, en el melodrama y el folletín de capa y espada; no más que la sublime 'Duquesa de Langeais' o la asombrosa 'Niña de los ojos de oro'. Flaubert reconstruye laboriosamente el palacio de Amnlcar con ayuda de centenares de pequeños detalles; del mismo modo procede con Yonville. En nuestra época, la novela histórica, o la que, por comodidad, puede denominarse asf, debe desarrollarse en un tiempo recobrado, animada por la presencia de un mundo interior.

El tiempo no cuenta. Siempre me sorprende que mis contemporáneos, que creen haber conquistado y transformado el espacio, ignoren que la distancia de los siglos puede reducirse a nuestro antojo" (5).

Hoy se escribe buena novela histórica (Robert Graves, Mújica Láinez, Umberto Eco, Alejo Carpentier, Abel Posse, Denzil Romero...), pero, sobre todo, "ahora el novelista no recrea la historia de forma novelesca, ateniéndose fielmente al hecho o a la anécdota, ahora la distorsiona, la inventa, llega a jugar con lo que es la más fuerte vertebración de la historia: el tiempo" (6).

Hemos llegado al núcleo central de la cuestión: la distorsión del parámetro tiempo, para fabular y recrear la historia. Las posibilidades son in(3) JACKSON, Gabriel, Por que escrib/ una novela historica. Historia-16, núm. 30, Madrid,
1978, págs. 129 a 132.

(4) Véase: LUKACS, George, La novela histórica. Era, México, 1966. RAMA, Carlos, La historla y la novela, Tecnos, Madrid, 1975. y 248.

(5) YOURCENAR, Marguerite, Memorias de Adriano. Edhasa, Barcelona, 1982, págs. 247

(6) CAMPOS, Jorge, Nueva relación entre la novela y la historia: Abel Posse y Denzil Romero. Insula, núm. 440-441, Madrid, 1983, pág. 19. 
mensas. La novela, como la historia, son totalmente subjetivas, pero ambas pretenden ser fieles al suceso histórico. Pensamos, por ello, que el momento elegido para examinar algunos aspectos de determinadas novelas históricas, es especialmente propicio. Asistimos, ya lo decfamos al princpio, a una renovación del significado de la novela histórica. Que está apoyada por la labor divulgativa de diversos medios culturales. Pensemos, por ejemplo, en el coloquio, que bajo el título Histoire et roman historique, tuvo lugar en el Centro "Georges-Pompidou", de París. En él participaron eminentes historiadores (G. Duby, M. Pierre, E. Vigne) y conocidos "romanciers" (J. Benzoni, M. Rayons), que coordinados por Jean-Jacques Brochier abrieron, el 2 de febrero de este año, un debate público.

Pensemos, también, en el periódico El País que dedicó la sección de "El Paŕs-Libros" del domingo 5 de febrero del año en curso, a la novela histórica. Lluis Racionero y Rafael Conte explicaron las relaciones entre "La historia, nuestra madre", y la novela, en "El diffcil ejercicio de reinventar el pasado."

Pensemos, por último, en la edición realizada por Alianza Editorial, de la Historia Universal "Asimov". ¿Habrá utilizado Isaac los recursos fundacionales de la psicohistoria de Harri Seldon?

\section{MELILLA EN LA VISION DE LA NOVELA HISTORICA: 1921}

El presente estudio pretende centrarse en la novela histórica en torno a la guerra de Marruecos. Concretamente en la guerra de 1921 y sus secuelas. El análisis tiene su nudo central en Melilla, sede de la comandancia militar de la zona oriental Marruecos, y se articula en torno a tres obras fundamentales:

- Ernesto Giménez Caballero: Notas marruecas de un soldado. 1.a edición: 1923.

- Ramón J. Sender: Imán. 1.a edición: 1930.

- Arturo Barea: La forja de un rebelde. 1. a edición -en castellano-: 1951.

Las ediciones manejadas por este trabajo han sido: para Notas marruecas de un soldado, Planeta, Barcelona, 1983; para Imán, Destino (2. ${ }^{\text {edi- }}$ ción), Barcelona, 1983; y, para La forja de un rebelde, Losada (4. a edición), Buenos Aires, 1966. A ellas van referidas cuantas notas aparecen en el desarrollo de este artículo.

Para centrar el tema cabe decir que la "cuestión marroqur" ha suscitado bastante literatura. El periodo reseñado, 1921, tiene sus antecedentes más claros, en la relación novela-historia, en la guerra de Africa de 1859-1860. 
Benito Pérez Galdós con su Aita Tettauen, 1905, en el contexto de sus Episodios Nacionales; y Pedro Antonio de Alarcón con su Diario de un testigo de la guerra de Africa, 1860, serfan exponentes y precursores de los autores escogidos para ilustrar los trágicos sucesos de 1921. De esta manera, como afirma Juan Goytisolo, "Ia denuncia de la guerra se integra en una corriente temática que ilustrarán más tarde con éxito autores como Sender o Barbusse..." (7).

Por otra parte, a la nómina de autores antes resefiada es posible añadir algunos otros, aunque sea de una forma más incidental, pero que tratan, igualmente, la cuestión suscitada. Asi Victor Ruiz Albéniz, que ha centrado buena parte de sus obras en la antigua zona del Protectorado español. Citaremos sus obras Ecce homo: las responsabilidades del desastre, Madrid, 1922, y su novela de ambiente marroqui, ;Kelb Rumi! La novela de un español cautivo en los rifeños en 1921, Madrid, 1921. Curiosamente, el propio Ruiz Albéniz denomina especfficamente muchas de sus obras. Asf: La carga de Taxdirt ("Narración histórica"); Los hijos de Allha ("Narraciones, tipos y costumbres de Marruecos"); Ben Alt Sherif, guerrero y redentor ("Novela sociológica del Mogreb"); etcétera.

Igualmente, hay que mencionar a Dlaz Fernández, autor de El Blocao, subtitulada, "Novela de la guerra marroqur", en la edición de Historia Nueva de 1928.

La obra de Luys Santa Marina, Tras el águila del César. Elegía del Tercio, 1921-1922, editada por vez primera en 1924, y reeditada por Planeta en 1980, contiene anotaciones sugestivas para nuestro estudio.

Por último, queremos reseñar dos novelas distanciadas en el tiempo -sus autores las han escrito mucho después de que los acontecimientos acontecieran-, pero no exentas de interés. Estas son, El Desastre de Annual, de R. Fernández de la Reguera y Susana March, editada por Planeta, y que forma parte de los llamados Episodios Nacionales Contemporáneos, del que forma el volumen núm. 7, y que apareció, en su primera edición en 1968; y, Kábila, de Fernando González, editada por Debate, Madrid, 1980.

Estas dos últimas novelas "históricas" son reconstrucciones muy posteriores a los hechos, pero que tienen interesantes perspectivas. El Desastre de Annual está concebido dentro de un aceptable rigorismo histórico, con un empeño voluntarioso y concienzudo de seguir la pista de Pérez Galdós. Kábila debe su mayor aporte de originalidad al tipo narración que el autor ha escogido. Así, será un auténtico kabileño el que hable en primera persona. $Y$ es a través de las andanzas del tuzani Ahmed Ben Haki como vamos conociendo el desarrollo de la evolución del personaje desde su en-

(7) GOYTISOLO, Juan, Crónicas sarracinas, Ruedo Ibérico. Barcelona, 1982, pág. 66. 
trada al servicio de los españoles -como "echador" de "kahua-el-halib" en el Casino Militar de Melilla - hasta su incorporación a las tropas nacionales que un 17 de julio se alzaron en Melilla, por supuesto, pasando por su activa participación en la guerra de 1921. Todo ello hace que "en Kábila se da un enfoque heterodoxo a los 'hechos de armas' acontecidos en el antiguo Protectorado español en Marruecos, por eso es un relato de malditos" (8).

La obra de Ernesto Giménez Caballero es la de un soldado de cuota que pasó dos años en Marruecos, en plena juventud, entre campamentos y hospitales.

La Ley de Bases de 29 de julio de 1911, la Ley del Servicio Militar de 12 de febrero de 1912, habfan suprimido la redención en metálico por el servicio militar, pero creaba el "soldado de cuota". Este podfa acortar su estancia en el Servicio mediante el pago de cierta cantidad al Estado. Así, el pago de 1.000 pesetas, reducra el Servicio a 10 meses; el pago de 2.000 pesetas lo reducra a solo 5 meses. Además de estas cantidades, el "cuota" debra pagarse el equipo, la manunteción y el caballo. La alternativa al cuota era el Servicio militar de 3 años para los menos afortunados.

De todas maneras una cosa era la teorfa y otra la realidad, Giménez Caballero, que llegó a Africa para sólo 5 meses, estuvo dos años.

La obra de Giménez Caballero tuvo mala aceptación por el Gobierno, dado que abanderaba el autor la postura abandonista. De todas maneras, a la hora de señalar diferencias, hay que decir que, al contrario de Sender y Barea, Giménez Caballero mantendrá una postura política -ya en la época franquista - que engarzará perfectamente en el franquismo, mientras que Barea y Sender tendrán que elegir la calle del exilio.

La sutil pluma del lector de Estrasburgo va cayendo sobre los tópicos y las realidades de la guerra de Marruecos, sobre "el héroe de los tres afios en tierras africanas, sometidos a todos los trabajos y penas" (9). Las descripciones, aunque concisas, son reales. $\mathrm{La}$ inquietud de los soldados que en el campamento despierten sorprendidos por una "ensalada de tiritos"; la pobreza del botín que hace que "los soldaditos espanoles en Marruecos se conformen con unos cuantos higos que birlan al Mohamed"; la presencia constante de la cantina junto a las guarniciones, en el campamento, en la plaza, figurando ser 'un modesto templo de alguna divinidad bené-

(8) GONZALEZ, Fernando, obra citada, pág. 7.

(9) GIMENEZ CABALLERO, $E_{*}$ obra citada, pág. 31. 
vola ad usum plebis"; la evocación de los compañeros cafdos como "el humilde Fernández, semilla de menestral o de burócrata, destrozada por el plomo"; el "Tercio de extranjis", repleto de "panteras africanas", etcétera.

Melilla se muestra ante sus ojos al final de una travesia en el "Giralda", acompañando al Alto Comisario con su séquito. Melilla aparece al doblar el cabo de Tres Forcas, con el faro destacado en la ciudadela vieja.

"Un antiguo teatro provinciano, enclavado en el casco de la Melilla vieja, allá en lo alto, como la atalaya de la ciudadela, fue habilitado para Residencia de nuestro más alto representante.

...En la fachada, encalada de rosa, con desconchones, aún se conserva intacto en letras grandes el título completo del teatro: 'Teatro Alcántara"' (10).

Pronto, Giménez Caballero siente la atracción de la Melilla vieja, a la que observa desde su alojamiento:

"Nostros, la tropa vulgaris, estamos alojados en un caserón frontero a la Residencia, que debio ser Casa Consistorial o algo asf; pues tiene una torre con reloj y grandes salas destartaladas... Abajo está la plaza en silencio... A la izquierda hay un palacio provinciano a cuya puerta espera un coche de mulas... A la derecha se abre el horizonte magn fficamente. El puerto, moderno, agradable, con algunos barcos de carga y de correo, con lanchones de pesca de mástiles abatidos, con dos navfos de guerra, y, a lo último, el "Giralda", negro, de tres altos palos, que cabecean suavemente. El mar está violeta, delicado. El Atalayón parece en él una colina encantada. Más a la derecha se alza el Gurugú famoso. Y bajo él, la ciudad nueva, impecable $y$, a esta hora, llena de vida, sobre todo en el muelle, donde descargan fardos, barricas, pacas, donde la gente pasea" (11).

Melilla se presenta aś como una ciudad salvada, aunque la población ha olvidado los sucesos de julio, el pánico, el deseo irrefrenable de huir.

"Me cuentan... cómo la población, ante el bombardeo, comenzó a refugiarse aqui, en este casquete de antiguas murallas, que tendria entonces el aspecto de la Melilla vieja de Estopinan."

"Esta Melilla vieja tiene encanto... Piedras venerables, doradas por los años, con inscripciones de tiempos de los Austrias en letras sugestivas. Callejones con sorpresas al mar... Hay casas con lápidas recordando refugios de castizos liberales espanoles. Callecitas que, iluminadas por un sol matinal, con sus geráneos en los balcones chiquitos, sus gatos y su soledad, huelen a Andalucía; Aquí está el arcaico caserón del Hospital, con galerías de arcadas. Aquí está el Faro..." (12).

(10) Ibidem, pág. 68.

(11) Ibidem, páss. 70 y 71 .

(12) Ibidem, págs. 71 y 72 . 
Decididamente Melilla la vieja cautiva a nuestro autor. Pero no podía faltar un "Paseo provinciano" por las calles de la Melilla nueva. Una ciudad que anuncia en la cotidianeidad de sus ruidos la atmósfera de paz.

"La Melilla nueva es una población seria. Tiene hermosas casas y hermosos comercios, algunos magn ificos. Es limpia, amplia, desarrollada. Por la noche, su calle central es una arteria llena de vida. Escaparates radiantes, cafés y kioskos de bebidas atestados... Las mujeres van a las compras de anochecer. Algunas visten muy bien y son bonitas. Suena el timbre del teatro de varietés. Y se olvida uno por un momento que está a dos pasos de ese Gurugu, que ayer ocupaban hos tilmente los moros" (13).

Es, en definitiva, una bella imagen de la ciudad, desmitificada porque el imponente y temido Gurugú es apenas un cerro. Este monte, cuyo nombre aterra al peninsular, en realidad, "no llega a ser una montaña". Sin embargo, Giménez Caballero se sorprende del descuido de no fortificar el Gurugú ".

Una vez más aparece la visión de Melilla arraigada en el mediodŕa peninsular.

"El parque... es un jardín de pronvicias del Sur o levantinas"(14).

Tras la estancia de unos pocos días en Melilla -incluida una visita a Nador- Giménez Caballero se aleja de nuevo en el "Giralda". Luego vendrán otra serie de descripciones, fundamentalmente de Tetuán, aunque no olvida Tamuda o Ceuta, o la transcripción de romances que conservan las hebreas xexuaníes. Al final realiza una delcaración de intenciones:

"He tenido gusto en recoger cosas que me han parecido pudieran servir como una modesta contribución a nuestra escasa literatura colonial. En el fondo, mi intención al publicarlas no es otra que dar testimonio de que en las generaciones de juventud española que hemos pasado por alli, hay alguien que diga algo" (15).

A la plácida visión de Giménez Caballero, Ruiz Albéniz añade una visión distinta, vista desde el prisionero de los Faquelán. Pero ésta es una vision anterior en el tiempo. Giménez Caballero habla después de pasado el desastre. Ruiz Albéniz, como Sénder, como Barea, hablan del desastre en si, de la pesadilla del soldado. Melilla aparece entonces como una remota esperanza, como el punto de enlace hacia la añorada Península. Muchos pasarán antes por el Purgatorio de la ciudad sitiada. Los enfermos "con pavor se ven luego en Melilla alojados en los pabellones Döcker, donde parece que no se respira que todo habla de dolor y muerte" (16).

(13) Ibidem, pág. 73

(14) Ibidem, pág. 74.

(15) Ibidem, pág. 185.

(16) RUIZ ALBENIZ, Víctor, ¡Kelb Rumil Le novela de un español cautivo de los rifeños en 1921. Librería y Editorial Rivadeneyra, Madrid, 1922, pág. 50. 
Peor suerte les esperaba a los cautivos. Abd-el-Krim los habla concentrado en Annual en su mayoría. Al desconsuelo de su situación se anfadra la intoxicación propagandística de los rifeños que afirmaban que "Melilla estaba medio derruida por efectos de los disparos de los cañones que Abd-el-Krim habia ordenado emplazar sobre el Gurugú" (17).

Giménez Caballero nos describe a Ruiz Albéniz, con el que coincide en un hotel de Tetuán. Lo describe como periodista "del que dicen que es muy entendido en cosas africanas. Su aspecto es el de un estudiante juerguista. Y sostiene teorfas sobre la gran inteligencia de los moros, que pasman" (18).

No vamos a comentar aquí la obra de Sénder, tan estudiada y conocida. Las limitaciones, propiamente impuestas, impiden una critica global de su obra. Sin embargo, cabe recordar que Sénder es un escritor comprometido y preocupado - en palabras de Manuel Béjar- por "los problemas más intrínsecos del ser humano... Tal preocupación aparece claramente en su primera novela Imán, ...donde, tras la ávida mueca del soldado, se busca el contacto amoroso con aquel otro ser primero suyo (vital entonces, hoy olvidado), mientràs el espeluznante refugio de la carrona sirve de marco adecuado -Jonás inédito del desierto, éste Viance - para el descubrimiento interior de una fe redentora: la comunión humana con la sustancia única, misteriosa y eterna" (19).

Ello es especialmente importante porque Imdn surge "en medio de la moda de la deshumanización del arte, de la novela pura y experimental" (20). Y surge Imán alineada con la obra de un grupo de escritores que buscan recoger la "realidad diaria dentro de un contexto social". Son José Díaz Fernández, Joaquín Arderius, César María Arconada y, poco después, Carranque de los Ríos.

Sénder se alinea en este grupo desde sus primeros escritos. Imán, su novela de la guerra de Marruecos, es la descarnada revelación de un antiherolsmo, la denuncia de unos hechos que apuntan a variados responsables, algo más que una "novela de guerra" tan en boga entonces en las

(17) Ibidem, pág. 235.

(18) GIMENEZ CABALLERO, E., obra citada, pág. 119.

(19) BFJAR, Manuel, Unidad y variedad en la narmativa de Sénder. Revista de Occidente, núm. 13, 1982, págs. 117 y 118.

(20) GARCIA VIÑO, Manuel, Novela española de postguerra. Publicaciones españolas, núm. 521, Madrid, 1974. 
traducciones de Remarque, Ludwig Renn o Barbusse. "El principio y fin de la novela llevan el relato desde el escenario de la guerra a una realidad española que colorea toda la trágica apopeya" (21).

Coincidiendo en lo expuesto por Manuel Béjar, Marcelino Peñuelas, en la introducción a Imán, explica que el título de la novela -que es el apodo del protagonista, Viance, en su aldea de origen-metamorfosea a esa España que atrae sobre sí misma la desgracia a través de su compleja y accidentada historia. Pero la atracción del imán es interpretada también positivamente como "amor", como "la a tracción natural entre las cosas y entre los hombres; la afinidad cósmica de que hablaba Manuel Béjar, refiriéndose al episodio en que Viance se ve obligado a buscar refugio en las entrañas abiertas de un caballo".

Es curioso como Goytisolo utiliza este sentido de imán, pero aplicado al moro "que atrae, como un imán, una colección de epitetos e imágenes crudamente raciales que se reiteran obsesivamente" (22).

Viance entra en contacto con Melilla avanzada ya en gran parte la novela. Imán ha salido indemne del desastre pero sufre el calvario de la huida y el intento, concluido al fin, de alcanzar la ansiada Plaza. Las descripciones son realistas y reales. No en vano el mismo Sénder nos dirá, muchos años después, que "En Imán tra tó de contar lo que sucedió. Estuve en lugar de los hechos, desde Melilla a Monte Arruit y a Kandussi y Dar Quebdani y Tizi Assa y Tistutin, en la campaña de reconquista, que fue larga y costosa. Con diez veces más fuerzas de las que mandaba Silvestre, quien como es sabido se suicidó en Annual, siguiendo los dictados de la noble tradición profesional." (23).

Desde la vaguadas del Gurugú, Viance se aproxima a Melilla. Las casetas del ferrocarril fortificadas como blocaos le señalan el camino. Por fin llega a las a fueras de la plaza:

"Ve las sombras del hipódromo, tiendas de campaña agrupadas. Líneas de alambradas y trincheras... Intenta dar la vuelta hacia el Real; pero las fortificaciones aumentan y el más pequeño ruido a trae los tiros de las ametralladoras. La ciudad está sumida en las sombras para dificultar el fuego de la artillería" (24).

Cuando por fin llega a la ciudad, la encuentra sumida en la defensa, asediada por los "pacos", falta de información. Apenas si le prestan atención y ha de emprender su particular vía crucis en busca del hospital.

(21) CAMPOS, Jorge, Sénder, escritor proletario. Insula, núm. 424, Madrid, 1982, págs. 4 y 5.

(22) GOYTISOLO, Juan, obra citada, pág. 11.

(23) SENDER, Ramón J., El valor de la novela histórica. Historia 16, núm. 2, Madrid, 1976, pág. 137.

(24) SENDER, Ramón J . Imdn. Destino, Barcelona, 1983, págs. 231 y 232. 
"Anda ya entre casas habitadas y pacificas. Este barrio es el Real y la calle de los prostŕbulos elegantes. Los soldados sólo vienen aquí cuando tienen mucho dinero, porque cae lejos del centro de la población y hay que coger un taxi'. Pero ahora las avanzadas están en el Real y la coincidencia es magnifica..." (25).

No es una ciudad amable la que acoge al "Ceriñola", más bien todo lo contrario. En el Alfonso XII, no se hacen cargo de él, y lo único posible es buscar su regimiento, atravesar toda Melilla hasta el Polígono, para luego subir hasta Cabrerizas Altas.

"La ciudad está dormida; pero se advierte pronto que no es un sueño reparador sino una pesadilla agitada, de pánico. Hay familias que marchan hacia el muelle con sus cuatro trastos, y otras se han trasladado al casco viejo de la población, que se alza en una especie de ciudadela fortificada, junto al mar. El miedo civil se ve en la prisa epiléptica de las mujeres que van y vienen por las cancelas de las casas de vecindad y el llanto dramático de algunas que gritan al ofr un nuevo cafionazo, o las ametralladoras lejanas, cuyo sonido recuerda el crotorar de las cigüeñas. Viance se detiene un momento en el umbral y es rodeado por varias mujeres. En vano quiere marcharse.

$-i$ De Serinola?: Es de Serifiola el pobresito" (26).

Pese a las compasivas frases, la realidad es que la población no quiere acoger a Viance. Continúa su camino atravesando el Polígono, azotado por el "levante", Arrullado por las casetas del Polf́gono duerme con rumores de marinería, prostitutas y alcohol. Del "Buen Tono" llegan lejanas voces. Por fin reanuda el camino "tan familiar", le renueva viejas impresiones. Roca monda, pelada; unas chozas al lado de la carretera, luego el paisaje muerto, gris plomo, sobre el cual emerge el alto rosetón del primer molino mecánico... Es para subir el agua al cuartel... Más arriba, otro molino sobre el alto trípode metálico" (27).

El cuartel es una nueva decepción: barracones de madera rodeados de un muro de almenas. Su barracón de transeuntes está lleno de "vagabundos, mendigos con las huellas del hambre, los uniformes destrozados, un aire general de miseria" (28).

Viance no entiende nada, cuando apenas llegado -en desastrosas condiciones - ha de partir de nuevo. Aquello es más misterioso que el "misterioso Selha ". Ya, Viance es una ruina física y moral. En estas condiciones es licenciado. Los trenes de San Juan de las Minas, que llevan el mi-

(25) Ibidem, pág. 234.

(26) Ibidem, pág. 240.

(27) Ibidem, págs. 243 y 244.

(28) Bidem, pág. 245. 
neral al muelle parecen despedirlo con cierta sorna. Al fin y al cabo "la Patria no es más que las acciones del accionista ${ }^{\text {" }}$ (29).

Como hiciera Giménez Caballero, Sénder, en una nota a la primera edición del año 1930, aclara que el libro simplemente "trata de contar la tragedia de Marruecos como pudo verla un soldado cualquiera de los que conmigo compartieron la campaña".

Otro tanto haría Díaz Fernández en su novela El blocao: "Marruecos sigue siendo una herida abierta en la conciencia española. A los espíritus civiles de aquellos soldados que fueron compañeros suyos en Marruecos de 1921, dedica el autor este libro" (30).

Annual, o mejor, el desastre de Annual fue sencillamente impresionante. La Comandancia de Melilla, a cuyo frente estaba Manuel Fernández Silvestre, no supo prever -en un error táctico o de apreciación- las consecuencias de un avance descabellado. Ceuta, Melilla y Larache -sedes de las tres Comandancias militares - no encontraron el modo de ejercer una fuerte influencia sobre sus territorios. "Fue precisamente el Rif (con 4.707 kilómetros cuadrados y 173.000 almas) núcleo de la berbería norafricana, el corazón de la resistencia marroquí en la zona española" (31).

El Rif, que contenía el mayor número de kábilas -22-y la mayor densidad de habitantes por kilómetro cuadrado $-36,74-$, infringió una dura lección al ejército español en Marruecos. En el verano de 1921 se contabilizaron 12.981 muertos, 14.000 fusiles, 100 ametralladoras, 115 cañones y gran cantidad de material. "El desastre de Annual supuso para el ejército de tierra, el golpe moral que la batalla de Santiago de Cuba había sido para la Marina en 1898. Una comandancia general entera habia desaparecido militarmente, y si Melilla no cayó en poder de los kalibeños, fue porque se dedicaron a recoger el inmenso botín desperdigado, pues Abdel-Krin era incapaz de imponerles una disciplina militar" (32).

Barea dedica el segundo libro de su trilogía La forja de un reblede -"La forja", "La ruta", "La llama"- a contar, de forma autobiográfica, su es-

(29) Ibidem, pág. 121.

(30) DIAZ FERNANDEZ, obra citada, pág. 5.

(31) MORALES LEZCANO, Víctor, El colonialismo hispano-francés en Marruecos (1898. 1927). Siglo XXI. Ed. Madrid, 1976, pág. 120. Siglo $X X I$,

(32) CARDONA, Gabriel, El poder militar en la España contemporánea hasta la guerna civil.

(31) MORALES LEZCANO, Víctor, El colonialismo hispano-frances en Marruecos (1898. 1927). Siglo XXI. Ed. Madrid, 1976, pág. 120.

(32) CARDONA, Gabriel, El poder militar en la España contemporánea hasta la guerra civil. Siglo XXI, Madrid, 1983, pág. 72. 
tancia en Africa como soldado. Aunque algunos autores -como Torrente Ballester - niegan a Barea el título de novelista, la realidad es que La forja de un rebelde es un espléndido documento, aunque como señala el profesor Riesgo, hay que tener en cuenta que cuando Barea escribe esta novela -en Ingla terra en el año 1944 la finaliza - "esta influido por la actuación del Ejército de Marruecos en la Guerra Civil (1936-1939). Sin embargo, la completísima obra, en gran parte autobiográfica, de Barea refleja un importante respeto hacia el rifeño como pueblo y como persona y no sólo admiración como combatiente" (33).

Encontramos al sargento Barea -Ingenieros- en una posición de Hámara, en junio de 1920. Su conexión con los naturales es notoria y la crítica hacia el opresor es demoledora:

"Durante los primeros veinticinco años de este siglo Marruecos no fue más que un campo de batalla, un burdel y una taberna inmensos" (34).

Su contacto con Melilla se debe a la "Derrota española de 1921" o "Desastre de Melilla", del que ya hemos hablado reiteradamente. Tras una marcha forzada de Xauen a Tetuán y Ceuta, son embarcados los refuerzos con rumbo a Melilla.

"En la Melilla sitiada, un barco panzudo volcó estos miles de hombres mareados, borrachos, agotados de cansancio, que iban a ser sus liberadores. Establecimos un campamento, no sé dónde. Oŕmos cañonazos, tableteos de ametralladoras, disparo de fusil de alguna parte fuera de la ciudad. Invadimos los cafés y las tabernas; nos emborrachamos y asaltamos las casas de putas. Putas y taberneros son imprescindibles en la guerra. Provocábamos a los habitantes asustados:"Ahora vais a ver lo que son cojones. ¡Mañana no queda un moro vivo!" ...A la mañana siguiente marchamos a las afueras de la ciudad: íbamos a romper el cerco y comenzar la reconquista de la zona " (35).

La descripción del horror es impresionante. Barea ya habra dicho: "Lo que yo conozco es parte de la historia nunca escrita..." (36), pero, incluso, se siente impotente para describir lo que ve, lo que huele -"olfamos a muerto" - por ello confiesa su impotencia.

"Yo no puedo contar la historia de Melilla de julio de 1921. Estuve allí, pero no sé dónde; en alguna parte, en medio de tiros de fusil... gritando, corriendo..., pero sobre todo vomitando sin cesar, oliendo a cadáver...

Un día al ama necer regresamos a la ciudad. Estaba lleno de soldados

(33) RIESGO PEREZ-DUEÑO, J. M., Coloquio sobre -Relaciones entre España y Africa-, en la UNED. Revista de Estudios In ternacionales, vol. 4, núm. 3, julio-septiembre, 1983, pág. 572.

(34) BAREA, A, obra citada, pág. 272.

(35) Ibidem, pág. 326 y 327.

(36) Ibidem, pág. 326. 
y de gentes que ya no estaban sitiadas. Vivían y réan. Se paraban en la calle para hablarse unos a otros, se sentaban en la sombra a beberse su aperitivo. Los limpiabotas se deslizaban entre la multitud de los cafes. Un aeroplano de plaza trazaba curvas graciosas en el aire. La banda de música tocaba un paso doble alegre en el paseo. Aquella tarde embarcamos" (37).

Giménez Caballero, Sénder, Barea, constituyen tres testimonios que saltan sobre el localismo de la guerra marroquí, para situarse en la guerra propiamente considerada. Terminamos con palabras de Sénder, que vuelven a destacar la importancia de las novelas como fuente documental y como testimonio histórico:

"Estoy convencido de que la novela moderna testimonial será mañana un documento vivo del mayor interés para los historiadores... creo que la novela que refleja el pensar y sentir del pueblo (lo que ahora se llama el -inconsciente colectivo- creador de mitos que van fijando los cimientos, los contrafuertes y las arquerfas del complejo edificio nacional), puede ser un testimonio histórico de especial valor. De tanto valor como el documento que certifica oficialmente los hechos y de más transcendencia en cuanto a los elementos de análisis y de interpretación necesarios para llegar a conclusiones certeras ${ }^{n}(38)$.

Por supuesto, no es posible realizar una reconstrucción exhaustiva de la Melilla de 1921 con la novela como única fuente. La prensa, los documentos oficiales y privados, y -cómo no- la fuente viva de la memoria histórica de la ciudad, guardada como patrimonio propio, coadyuvan en la busca del tiempo pasado.

(37) Ibidem, págs. 328 y 329.

(38) SENDER, R. J., El valor de la novela histórica, págs. 136 y 141. 